\title{
CONTENIDOS GENERADOS POR LOS USUARIOS Y PERIODISMO
}

\author{
USER-GENERATED CONTENT AND JOURNALISM
}

\author{
Amaro La Rosa Pinedo ${ }^{1}$
}

\section{RESUMEN}

El artículo se enfoca en una aproximación al papel de los contenidos generados por los usuarios en el periodismo, partiendo de una visión de la comunicación en la era de internet y de las redes sociales. Se presenta evidencia científica sobre el particular.

\section{Palabras clave}

Periodismo, contenido generado por el usuario (CGU), internet, comunicación, redes sociales

\section{ABSTRACT}

The article is focused on one approach to the role of the user-generated content in journalism, starting from one vision of the communication in the age of Internet and social media. Relevant scientific evidence is provided.

\section{Keywords}

Journalism - User generated content, internet, communication, social networking

\section{LAS REDES SOCIALES, COMUNICACIÓN Y EL MUNDO}

A lo largo de la historia, el ser humano se ha comunicado con sus semejantes de diversas maneras y con propósitos varios. Sus posibilidades de interacción colectiva se han ido incrementando y modificando paso a paso, en función de la evolución de la sociedad y del desarrollo de la tecnología, cuyo ritmo ha crecido aceleradamente en las últimas décadas del siglo XX y lo que va del XXI,
LA En consonancia con ello, las redes sociales en las cuales estamos integrados los actores sociales han variado sustancialmente sus modalidades del intercambio comunicativo. De la noción de prosumidores planteada por Toffler (1980), de modo prospectivo para referirse a los individuos quienes desempeñan a la vez los roles de productores y consumidores, se concibe ahora que con el surgimiento de la Web 2.0 es posible actuar como produsuarios (Bruns, 2006), vale decir, individuos quienes actúan produciendo y utilizando información a nivel global. Estos

Lic. En Psicología y Periodista Profesional. Docente-investigador en UNIFÉ y en la Universidad Jaime Bausate y Meza. Es autor de 15 libros publicados en el Perú y de artículos en 17 libros publicados en el Perú, Suiza, Ecuador, España, Alemania y Estados Unidos. 
seres humanos se integran en redes que facilitan la producción de contenidos propios y el intercambio de mensajes de diverso orden entre los usuarios. Estas redes para Campos, (2008) trastocan los modelos tradicionales de medios de comunicación.

La naturaleza interactiva y la inmediatez de las avanzadas herramientas de la web 2.0 han hecho posible la puesta en marcha de múltiples conexiones entre los seres humanos y han motivado una activa participación social de los individuos, grupos y comunidades, atravesando las fronteras $e$ inclusive desafiando las restricciones al uso de internet que han intentado imponer regímenes autoritarios que se creían invulnerables. Medios Sociales como Facebook y Twitter representan ahora recursos clave para el intercambio comunicativo y comercial en la sociedad contemporánea.

La importancia de Youtube y de Facebook se evidenció durante la denominada primavera árabe, contribuyendo tanto a movilizar a la comunidad como a difundir lo que sucedía a nivel global. Las cifras de Twitter son también bastante significativas. La Copa Mundial de fútbol Brasil 2014 generó 672 millones de tweets y el triunfo de Alemania 618725 tweets por minuto.

Un selfie subido a Twitter puede convertirse en viral y alcanzar rápidamente récords

Figura 1.

El tuit más retuiteado de la historia

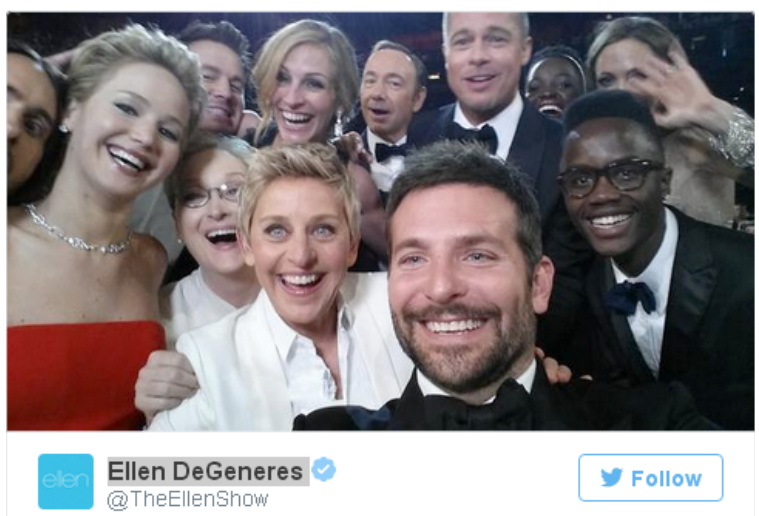

If only Bradley's arm was longer. Best photo ever. \#oscars que pueden parecer increíbles. El que fuera registrado por la conductora Eleen DeGeneres durante la ceremonia de entrega del Oscar 2014 y colgado en Twitter en vivo logró más de un millón de retuits en 50 minutos y es, hasta el momento, el más retuiteado de la historia (Figura 1). En ese momento, DeGeneres tenía más de 13 millones de seguidores que al 4 de setiembre de 2015 alcanzan 47,111,339.

Sin embargo, hay selfies que han generado un marcado rechazo y generado polémica inclusive antes de su publicación. El 28 de julio de 2015, luego del último mensaje a la nación de su gobierno, el Presidente Ollanta Humala daba un discurso en el frontis de Palacio de Gobierno acompañado por sus ministros y su esposa. Mientras ello ocurría, el Ministro del Ambiente Javier Pulgar Vidal se entretenía tomándose un selfie con otros ministros frente a las cámaras de TV. Los comentarios no se hicieron esperar tanto en los medios como en las redes sociales. Días después, el Ministro lo publicó en su cuenta de Twitter (Figura 2).

Figura 2.

El Tuit del Ministro

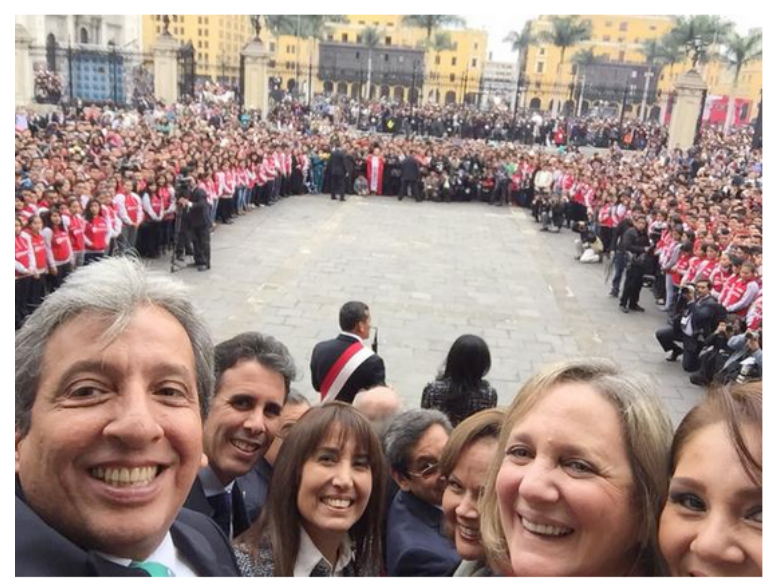

Manuel Pulgar Vidal

t2 Seguir

Para los peruanos capaces de alegrarse con su país y empujar con solidaridad e integración el desarrollo. Va la foto. 


\section{ACERCA DEL CONTENIDO GENERADO POR LOS USUARIOS (CGU)}

El contenido generado por los usuarios es para el Interactive Advertising Bureau (2008) todo material creado y subido a la red por personas que no son profesionales de los medios. En términos generales, nuestro criterio es concordante, entendiendo tanto individuos como a colectivos agrupados en lo que se conoce como crowdsourcing.

La construcción de la realidad en los medios de comunicación es una tarea compleja cuyo análisis intentamos en un trabajo reciente (La Rosa, 2013) donde desmontamos los procedimientos que se desarrollan al interior de los medios de comunicación en sus diversas plataformas. En la actualidad, ese entramado en el cual se construyen las informaciones (newsmaking) cumplen en rol importante los CGU. Stanoevska-Slabeva y Sacco \& Giardina (2012) anotan que el creciente rol activo de las audiencias en la creación de las noticias está modificando las relaciones entre los medios y periodistas en relación a sus lectores.
Algunos autores estiman que los CGU condicionan necesariamente el contenido de los medios de comunicación. HerreroCuriel (2012:1117) afirma "Hoy en día la audiencia puede interactuar con los nuevos medios y el rastro que va dejando en la web a través de sus comentarios, búsquedas o publicaciones pasa a formar parte del contenido mediático". A decir de Rublescki (2009: 13-14) el CGU constituye un aporte para la libertad de expresión al ampliar los emisores con nuevos criterios sobre la noticiabilidad $y$, por ende, con diversidad de contenidos para la agenda pública. En principio, no podemos dejar de reconocer el impacto de los CGU y de su utilización en los medios, pero estimamos que ello no supone necesariamente el pase irrestricto de cualquier tipo de recurso.

Scott (2009:36) plantea una taxonomía sobre las formas de CGU que adapta del estudio de Wardle y Williams (2008) que fuera realizado para la BBC por la Universidad de Cardiff (Tabla 1).

Tabla 1:

Tipos de CGU. Elaboración propia basada en Scott (2009: 36)

\begin{tabular}{|l|l|l|}
\hline TIPO DE CGU & DESCRIPCIÓN Y USO & EJEMPLOS \\
\hline $\begin{array}{l}\text { Contenido informativo } \\
\text { generado por la audiencia }\end{array}$ & $\begin{array}{l}\text { Formas de CGU utilizadas } \\
\text { en las noticias: Imágenes, } \\
\text { experiencias y nuevas } \\
\text { historias. }\end{array}$ & $\begin{array}{l}\text { Fotografías, audio y video de } \\
\text { noticias de última hora, estudios } \\
\text { de casos y trucos y consejos. }\end{array}$ \\
\hline Comentario de la audiencia & $\begin{array}{l}\text { Expresiones de la opinión de } \\
\text { la audiencia. }\end{array}$ & $\begin{array}{l}\text { Contribuciones en la red a foros } \\
\text { de debate o llamadas telefónicas } \\
\text { a la radio. }\end{array}$ \\
\hline Contenido cooperativo & $\begin{array}{l}\text { Contenido no informativo } \\
\text { producido mediante la } \\
\text { colaboración entre medios y } \\
\text { espectadores. }\end{array}$ & $\begin{array}{l}\text { Cortometrajes, biografías } \\
\text { personales. }\end{array}$ \\
\hline Periodismo interactivo & $\begin{array}{l}\text { Creación cooperativa de } \\
\text { contenidos informativos. }\end{array}$ & $\begin{array}{l}\text { La audiencia investiga y añade } \\
\text { sus experiencias y conocimientos } \\
\text { a las noticias. }\end{array}$ \\
\hline Otro contenido & Toda otro tipo de material. & $\begin{array}{l}\text { Revistas, imágenes no } \\
\text { informativas, recomendaciones. }\end{array}$ \\
\hline
\end{tabular}


Los primeros diarios digitales eran prácticamente copia y pega del material publicado en los diarios impresos. Pero en la medida en que la tecnología avanzaba, fueron diferenciándose e introduciéndose cambios tanto en el aspecto formal como en el propio contenido. Al desarrollarse la web 2.0 paulatinamente se fueron incorporando sus recursos y con ellos los CGU. El estudio de García de Torres (2012) destaca que en la propia portada de los diarios digitales se reconoce el contenido generado por el usuario (CGU), tal como lo presentamos en la tabla 2.

Tabla 2.

CGU en portadas de diarios digitales. Fuente: García de Torres (2012)

\begin{tabular}{|c|c|}
\hline ELEMENTOS & FRECUENCIA \\
\hline Encuesta & $67 \%$ \\
\hline Lista de contenidos más vistos & 62,5 \\
\hline Sección de blogs & $50 \%$ \\
\hline Sección de participación & 42,5 \\
\hline Número de comentarios por noticia & 31,2 \\
\hline Solicitud de fotos y videos & $25 \%$ \\
\hline Sección de lo más visto & $21,2 \%$ \\
\hline Llamada a comentar las noticias & $21,2 \%$ \\
\hline Petición explícita de envío de noticias & 16,2 \\
\hline
\end{tabular}

Evidentemente, por su propia naturaleza, no todos los CGU tienen las condiciones para ser presentados a la audiencia, pues a pesar de las buenas intenciones que puedan tenerse se trata de materiales producidos por personas quienes no son profesionales en comunicación y, por ende, desconocen las normas y criterios de producción así como el manejo de los códigos del medio o de la plataforma que emplean. Tal como lo hemos anotado explícitamente en otros acápites, en este caso resulta vital el rol del especialista quien debe filtrar, regular y sobre todo contrastar la información.

Wardle y Williams (2010: 789) describen que el uso de los CGU para la BBC puede implicar las siguientes categorías:

- Encontrar nuevas fuentes

- Generar historias noticiosas

- Facilitar espacio para la discusión pública y el debate

- Reforzar las relaciones con la audiencia

- Descubrir material para segmentos no noticiosos

- Empoderar a la audiencia
Un estudio de Atkins (2010) se basa en encuestas a directivos de noticias de televisoras en diversas ciudades de Estados Unidos. Encuentra que a pesar de reconocer que su calidad es inferior a la que posee la producción propia, los videos generados por los usuarios (VGU) se incorporan como material informativo. Tanto más, los directivos afirman que se buscan oportunidades diversas para incrementar el uso de estos recursos. Durante los últimos sismos ocurridos en el Perú diversas personas hicieron tomas con sus cámaras de video y sus teléfonos móviles, las subieron a la red o las enviaron a las emisoras de televisión como testimonios de los momentos críticos. Desde luego, no era la primera vez que esto sucedía pues se había registrado previamente en el maremoto de Malasia y en el de Japón así como en los videos tomados durante el $11 \mathrm{M}$.

Meso (2013) constata que las herramientas de la web 2.0 han modificado las modalidades de búsqueda, selección, acceso y distribución de información. Ahora bien, los medios de comunicación reciben numerosos CGU cada día. Para poderlos presentar a la sociedad deben someterlos a un procesamiento para analizar su noticiabilidad y su ajuste a los estándares del medio; en esa medida, en caso de que los contenidos sean categorizados como inapropiados se descartan, en tanto que los apropiados se incorporan. Sin embargo, sucede que ciertos CGU son captados directamente en una sociedad, sin pasar por los medios. Así por ejemplo un video se convierte en muy corto tempo en viral o un tweet se retuitea con rapidez e impacta a la sociedad. En este último caso se incorporaría al medio sin mayor procesamiento o se procedería a un reprocesamiento (Figura 3)

Paulussen \& Ugille (2008) realizan un estudio cualitativo en tres diarios de Bélgica. Concluyen que a los periodistas evalúan la noticiabilidad, el tono personal y la subjetividad de los CGU, pero entienden que su procesamiento supone una sobrecarga de trabajo.

Un estudio comparativo de la información sobre el conflicto de Siria en BBC en árabe y en 
Figura 3.

Rutas del CGU. Elaboración propia basada parcialmente en Meso (2013)

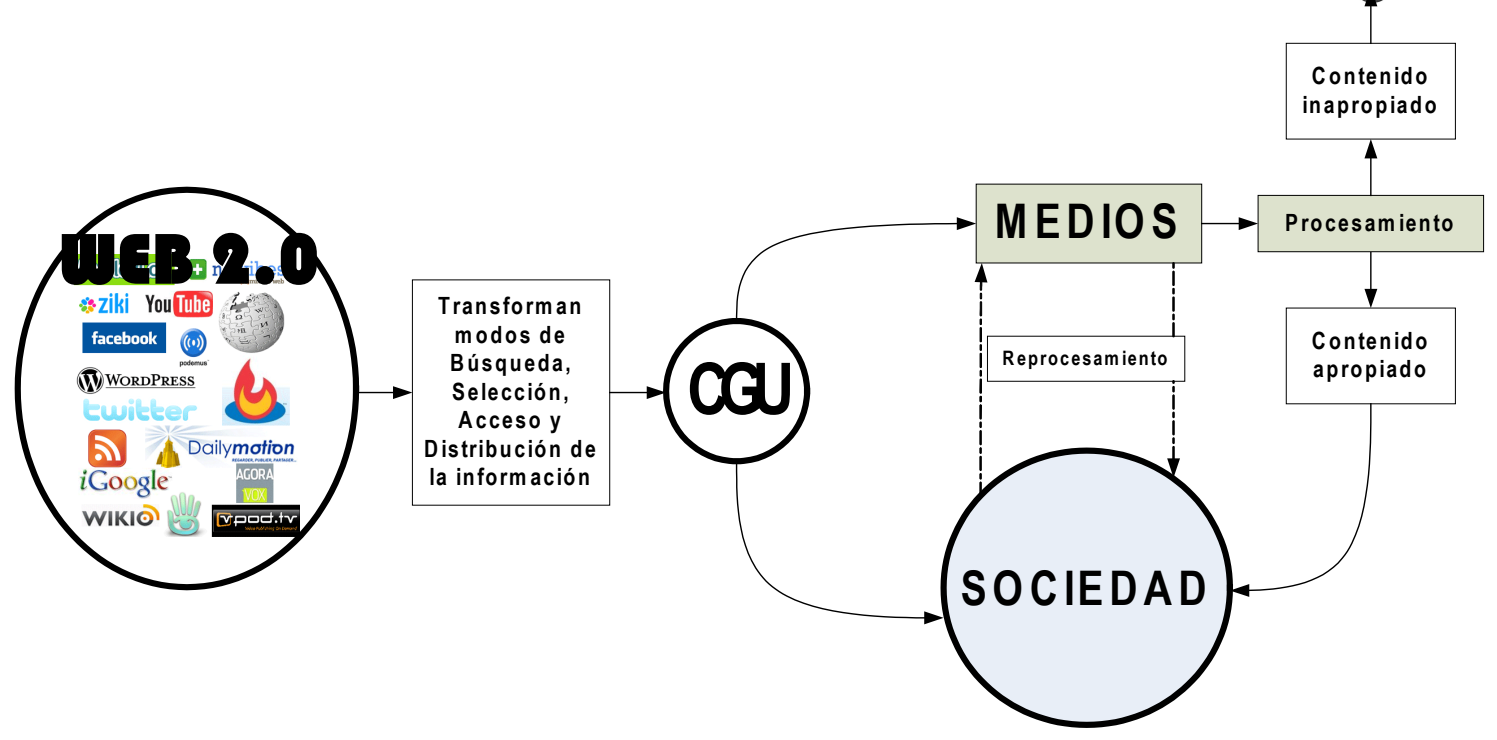

Al Jazeera muestra claramente las previsiones que deben tomarse con respecto al CGU y las orientaciones al personal profesional que recibe información en una situación de crisis en la cual existen dificultades y elevados riesgos para la cobertura periodística (Harkin, Anderson. Morgan y Smith (2012). Los CGU no necesariamente funcionan de la misma manera en todas las culturas.

En la tesis de Solanki (2011) se analizó el contenido de cinco diarios online de la India y cinco de países occidentales durante el lapso de una semana para conocer el grado y la naturaleza de participación de los usuarios con sus contenidos. El consolidado de los resultados aparece en la tabla 3.

Tabla 3.

Participación de usuarios. Basado en Solanki (2011)

\begin{tabular}{|l|l|l|}
\hline ATRIBUTO & DIARIOS DE LA INDIA & DIARIOS OCCIDENTALES \\
\hline Comentarios & 11,503 & 2769 \\
\hline Facebook & 5,657 & 6,974 \\
\hline
\end{tabular}

Del mismo modo, la credibilidad en los CGU no es necesariamente la misma en todos los integrantes de la audiencia. También depende, por cierto, de las características de los usuarios. Sobre el particular, Wang (2015) encuentra que la credibilidad percibida de los CGU de Youtube está positivamente correlacionada con las actitudes hacia los CGU y que en lo referido a las actitudes hacia los CGU existe una marcada diferencia entre los usuarios activos y pasivos.

\section{A MODO DE CIERRE}

Son ingentes y urgentes las tareas para los profesionales de la comunicación en este terreno. Resultan bastante complejas por una serie de razones, entre otras, porque las audiencias demandan ser cada vez más participativas por lo cual es necesario plantearse fórmulas enriquecedoras de uso del CGU e igualmente porque cada vez más los medios se convierten en conglomerados multiplataforma, con nuevas exigencias para el trabajo profesional del periodista. 


\section{REFERENCIAS}

Atkins, C. (2010) Broadcast news organizations' perception of viewer generated content. Thesis Master of Arts in Communication, Marshall University.

Bruns, A. (2006) Towards Produsage: Futures for User-Led Content Production. In Sudweeks, Fay and Hrachovec, Herbert and Ess, Charles, Eds. Proceedings Cultural Attitudes towards Communication and Technology, pages pp. 275-284, Tartu, Estonia.

Campos, Francisco (2008): "Las redes sociales trastocan los modelos de los medios de comunicación tradicionales", en Revista Latina de Comunicación Social, 63, páginas 287 a 293. La Laguna (Tenerife): Universidad de La Laguna. Acceso: 20 de marzo de 2014. Disponible: http://www.ull.es/publicaciones/latina/_2008/23_34_Santiago/Francisco_Campos.html

García de Torres, E. (2012) Estudio internacional de las herramientas de participación en la prensa digital. En García de Torres, E (Coord.) Cartografía del periodismo participativo Valencia: Tirant Humanidades, 59-120

Harkin, J., Anderson, K.. Morgan, L. y Smith, B. (2012) Deciphering user-generated content in transitional societies: A Syria coverage case study. Center for Global Communication Studies, Annenberg School for Communication, University of Pennsylvania.

IAB (2008) User Generated Content, Social Media, and Advertising — An Overview April (Online paper). Acceso Agosto 25 2015. Disponible:

http://www.iab.net/media/file/2008_ugc_platform.pdf

La Rosa, A. (2013) Construcción de la agenda mediática: Una mirada al interior de la comunicación. Lima: Universidad de San Martín de Porres

Meso, K. (2013) Periodismo y audiencias: inquietudes sobre los contenidos generados por los usuarios. Cuadernos.info, 33, 63-73. DOI: 10.7764/cdi.33.515

Paulussen, S. \& Ugille, P. (2008) User Generated Content in the Newsroom: Professional and Organisational Constraints on Participatory Journalism, Westminster Papers in Communication and Culture Vol. 5(2): 24-41. Acceso: 15 agosto de 2015. Disponible:

http://jclass.umd.edu/classes/jour698m/paulussen.pdf

Rubleski, A. (2009) Jornalismo e Conteúdo Gerado pelo Usuário: uma Discussão sobre Credibilidad. Trabalho apresentado no XXXII Congresso Brasileiro de Ciências da Comunicação - Curitiba, PR - 4 a 7 de setembro

Scott, M. (2011) Guía para radios y televisiones sobre la promoción del contenido generado por el usuario y la alfabetización mediática e informacional. Barcelona: Editorial UOC

Solanki, M. (2011) A study of online readers participation in context of interactivity debate: comparison between Indian and Western newspapers, Thesis. M Phil, Department of Jounalism \& Mass Communication Maharshi Dayanand University, Rohtak, India

Stanoevska-Slabeva, K., Sacco. V. \& Giardina, M. (2012) Content Curation: a new form of gatewatching for social media?, Paper presented at the 2012 International Symposium on Online Journalism, Austin 
Toffler, A. (1980) La Tercera Ola, Bogotá: Plaza \& Janes Editores

Wang, C. (2015) Do People Purchase What They Viewed from YouTube? the Influence of Attitude and Perceived Credibility of Use-Generated Content on Purchase Intention" Thesis MS, School of Communication, Florida State University

User Generated Content in the Newsroom: Professional and Organisational Constraints on Participatory Journalism

Wardle, C. y Williams, A. (2008) UGC@theBBC: Understanding its Impact upon Contributors, Noncontributors and BBC News. Cardiff School of Journalism.

Wardle, C. y Williams, A. (2010) Beyond user-generated content: A production study examining the ways in which UGC is used at the BBC. Media, Culture and Society, Vol 32 (5), 781-799

Fecha de recepción: 07 de julio 2015

Fecha de aceptación: 21 de agosto 2015 